Supplement of Biogeosciences, 15, 5699-5713, 2018

https://doi.org/10.5194/bg-15-5699-2018-supplement

(C) Author(s) 2018. This work is distributed under

the Creative Commons Attribution 4.0 License.

(c) (1)

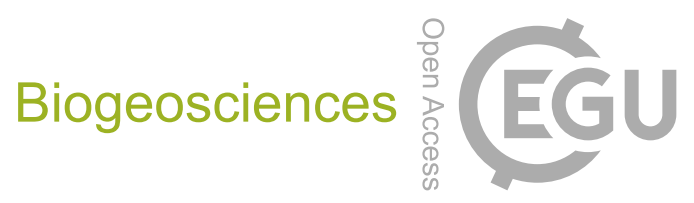

Supplement of

\title{
Legacies of past land use have a stronger effect on forest carbon exchange than future climate change in a temperate forest landscape
}

Dominik Thom et al.

Correspondence to: Dominik Thom (dominik.thom@uvm.edu)

The copyright of individual parts of the supplement might differ from the CC BY 4.0 License. 


\section{Section S1: Historical data}

\section{Archival sources}

3 All archival sources were obtained from the archives of the Austrian Federal Forests

4 (Österreichische Bundesforste), located in Purkersdorf, Austria. The material consists of maps,

5 quantitative documentations (e.g., tables of growing stock per species and stand), and verbal

6 descriptions of vegetation state, natural disturbances, and forest management. We compiled

7 these sources by means of photographical documentation and subsequent transcription.

9 The full list of sources are:

10 Revisionsoperat des K.K. Wirtschaftsbezirkes Reichraming 1903-1912

11 Revisionsoperat für den K.K. Wirtschaftsbezirk Reichraming 1913-1922

12 Wirtschafts-Buch für den k.k. Wirtschaftsbezirk Reichramming 1903-1926

13 Reichraming 1938-1947 [data for the period 1927-1937]

14 Gedenkbuch 1950-1959 FV. Reichraming

15 Gedenkbuch 1960-1969 FV. Reichraming

16 Gedenkbuch Reichraming 1970-1983

17 Revisions-Operat für den K.K. Wirtschaftsbezirk Weyer (Steiermärkischer Religionsfonds)

$18 \quad 1902-1911$

19 Revisions-Operat für den K.K. Wirtschaftsbezirk Weyer (Steirm. Fondsforst) 1912-1921

Weyer 1928-1937 
Wirtschaftsbuch begonnen mit dem Jahr 1902 (Weyer, Oberösterreichischet Religionsfonds)

Waldbesitz Ebenforst der Herrschaft Steyr. Flächentabelle, Bestandsbeschreibung,

Altersklassen Verzeichnis nach dem Stande 1898

R. Klöpferscher Waldbesitz Reichraming, Revier Ebenforst. Stand 1. April 1947 [Map]

R. Klöpfer'scher Waldbesitz Reichraming, Revier Weissenbach, Stand 1. April 1947 [Map]

Nikolaus'scher Waldbesitz Reichraming, Revier Weissenbach, Stand 1. I. 1964 [Map]

Nikolaus'scher Waldbesitz Reichraming, Revier Ebenforst. Stand 1. I. 1947 [Map]

Waldwirtschaftsplan 1974-1983 Forstwirtschaftsbezirk Karl Heinrich NICOLAUS, 4462

Reichraming.

Betriebseinrichtungs-Elabort vom Reviere Zeitschenberg O.Ö. 1907

W.B. Rosenau 1950-1959

From these sources, two types of data were extracted: First, spatially explicit data at the level of stands for the entire study landscape (see Fig. S1). These data represent the best available historical information, and were available for certain points in time (or multi-year inventory periods). Specifically, spatially explicit inventories on the forest state were available for the periods 1902/03, 1912/13, and 1926/27 (see Fig. S2). In addition, stand-level data on natural disturbances and anthropogenic disturbances (harvesting) were available for the period 1902 - 
annual resolution (source materials for the forest districts Weyer and Reichraming). These data were used to analyze the annual variation in harvest levels. They were furthermore analyzed for major disturbance events. In addition we screened the written protocols and examined meteorological data with a particular focus on detecting major disturbance events outside the two well-documented disturbance episodes 1917-1923 and 2007-2013. These analyses showed that no notable disturbance events occurred between the two major periods analyzed explicitly here.

\section{Identification of spatial units}

The delineation of forest stands started in the 1880s in our study area. In most cases, the boundaries of these stands were found to be still valid today, however, minor changes have been made over time (these are well-documented in the forest inventory sources). The spatial identification of stand units was done case by case, comparing toponyms, stand shapes and sizes between historical and recent maps. This approach allowed us to link data spatially between different time periods, and to evaluate the congruence of spatial units between periods. Minor reduction in the size of stand polygons was frequently detected, and was usually attributable to the construction of roads and other infrastructure. In some cases, changes in the stand configuration were made (particularly in remote high-elevation areas of the landscape), which were accounted for by subdividing the respective polygons.

\section{Data gaps}

Forests that were under federal ownership throughout the study period were found to be best documented. Two areas in the northern reaches of the landscape were under different 
ownership, but were sufficiently well documented to retain them in our study. These areas have previously been part of the domain Lamberg, and cover about 1/6 of the total landscape. Nonetheless, a number of data gaps had to be filled to achieve a complete and seamless reconstruction of landscape history.

To fill data gaps regarding the temporal variation in natural disturbance and land use we assumed equivalence in relative changes, i.e., based on harvesting rates in a given year for a certain area, we assumed an equivalent change also for areas with missing data. For instance, after 1923 time series on annual harvest and natural disturbance were only available for the forest districts of Reichraming and Weyer (the two main historic forest districts in our study area, covering in total 4492.4 ha). Moreover, Reichraming is lacking data for the years 1938 to 1946 , hence the temporal variation of harvests was only based on the data for Weyer during this period. The data for Weyer terminates in 1952, i.e., only data from the district Reichraming was available for the following years. Where the time series of the two forest districts overlapped, we found similar trends in Reichraming and Weyer, supporting our assumption of equivalence between the two areas. 


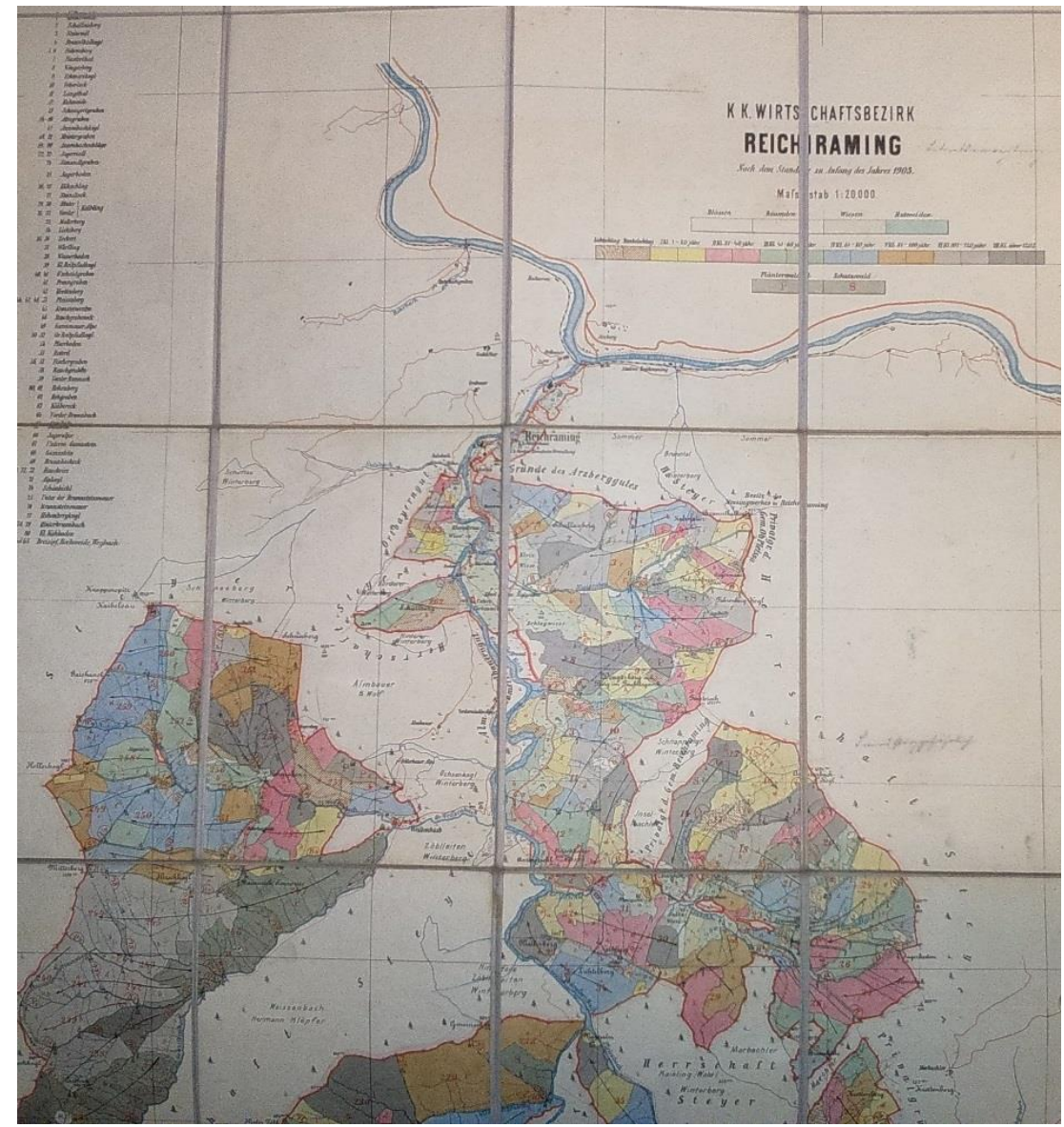

81 Fig. S1: Example for a map extracted from archival sources, showing a segment of the forest

82 district Reichraming in 1903. The colors denote different age classes of forest stands. 


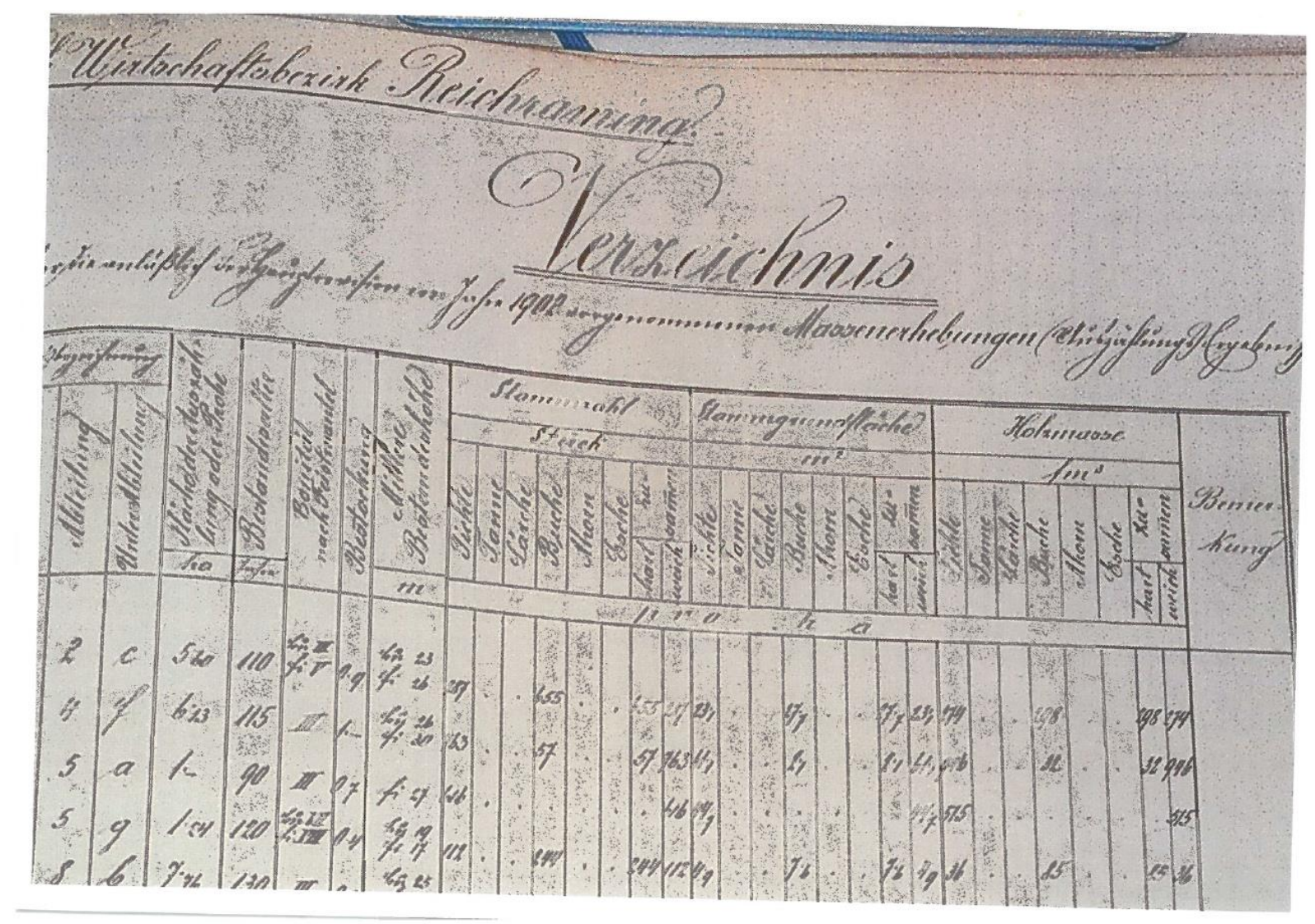

83

84 Fig. S2: Example for an inventory table extracted from archival sources, showing stem number

85 (Stammzahl), basal area (Bestandesgrundfläche) and growing stock (Holzvorrat) per tree 86 species and stand. 


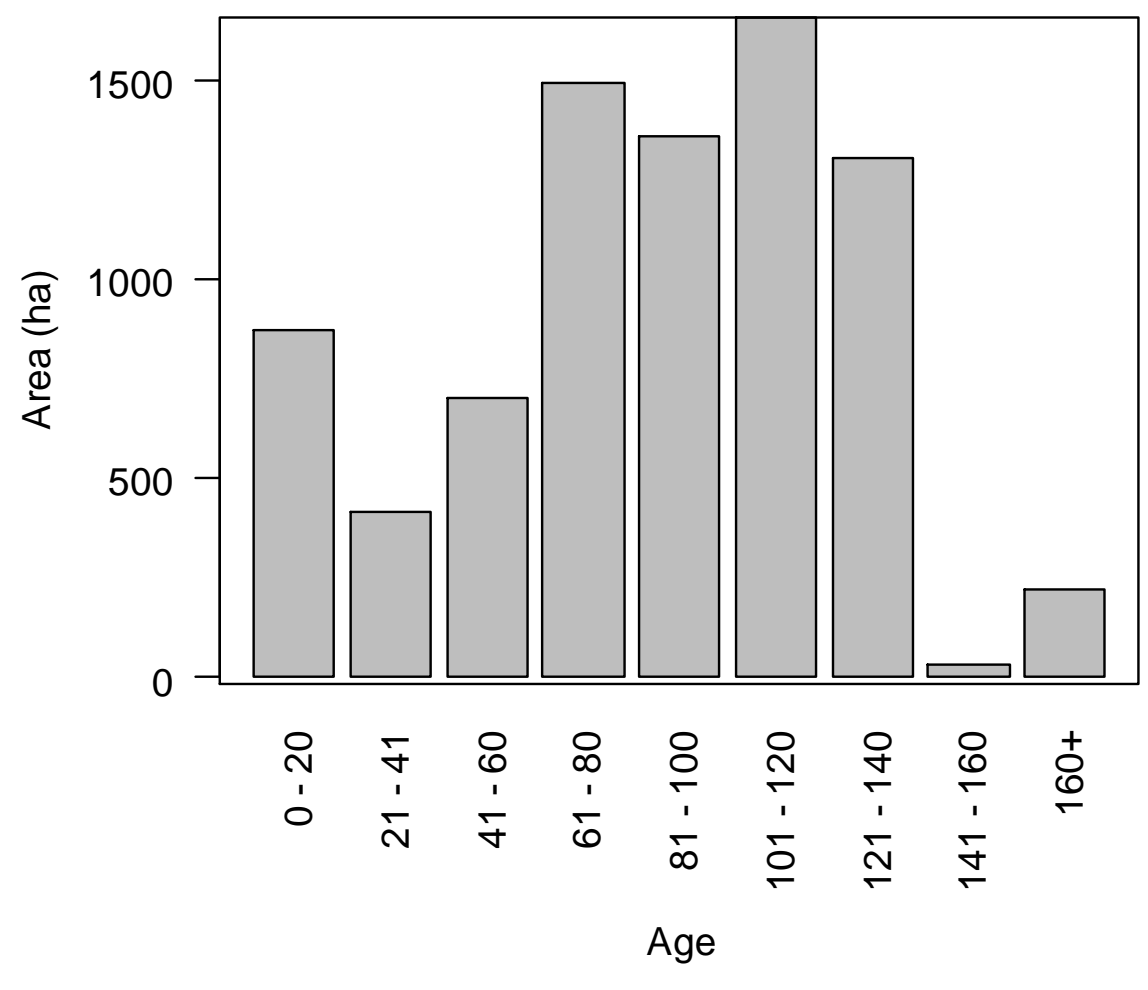

88

Fig. S3: Age distribution across the study landscape in 1905. 


\section{Section S2: Legacy spin-up}

\section{Legacy spin-up procedure}

Management and disturbance history have a long-lasting influence on forest stands, and are important determinants of the state of a forest at any given point in time. In forest landscape models, the initialization of the state of the ecosystem accounts for legacies of past land use and disturbance. However, the information provided upon initialization differs considerably between models (e.g., Garcia-Gonzalo et al., 2007; Schumacher and Bugmann, 2006; Thom et al., 2017) and is crucially determined by model structure. For instance, while structural information plays only a minor role in cell-based simulation models (Scheller et al., 2007), individual-based models retain information about tree dimensions, canopy heights, gaps, regeneration etc. (Seidl et al., 2012). Yet, detailed information about forest ecosystem attributes for initializing simulation models is oftentimes not available (e.g., the spatial patterns of past disturbances or soil carbon stocks). This is important as uncertainties in initialization can have substantial influence on the simulated trajectories (Temperli et al. 2013).

Using models enables the simulation of past forest development, including past management and disturbances, in the form of a spin-up run. Models can thus help to create realistic and quantitative past and current states of forests. In a conventional spin-up, the model is run for an extended period of time under past forcing, and a snapshot of the simulated state is taken-after reaching a predefined stopping criterion (e.g., elapsed time, variation in certain C pools) - as the starting point for scenario analyses (Thornton and Rosenbloom 2005). This results in meaningful estimates regarding important ecosystem properties, and a system state that is consistent with the internal model logic. However, thus derived ecosystem states often do not correspond well with the information available from past and current observations. For instance, a stand that was recently disturbed in reality could be initialized in a late-seral stage from a 
spin-up. This lack of structural realism strongly limits the utility of a traditional spin-up approach for initializing models for future projections. Factors such as the spatial distribution of age cohorts on the landscape have important implications for the future ecosystem dynamics, e.g., in the context of future susceptibility to disturbances. Therefore, we have developed a new spin-up approach, termed legacy spin-up, aiming to assimilate available data on the ecosystem state at a given point in time into the spin-up procedure, in order to improve the correspondence of the model state derived from spin-up with the observed state of the system.

Our approach differs from conventional model spin-up by considering the available information of the state of any given stand on the landscape for a reference point in time (Fig. S4). As with a conventional spin-up, the legacy spin-up starts by running the model over an extended period of time. This results in a large number of possible states that a given stand on the landscape can be in, given the prevailing climate and soil conditions as well as the past management and disturbance regime. From this state space of each stand, the legacy spin-up procedure selects the state that corresponds most closely to the reference values available for each stand (e.g., observed values from forest inventories, remote sensing, or archival data). In other words, the legacy spin-up does not simply use the vegetation state of the last year of the spin-up run for all stands as initial condition for scenario analysis, but for each stand identifies the specific year of the spin-up run in which the state of the vegetation corresponds most closely to the reference conditions.

To improve the correspondence between the simulated state space for each stand and the reference conditions we harness the adaptive capacity of the agent-based forest management module (ABE) integrated into iLand (Rammer and Seidl, 2015). As detailed information on historic management is usually not available, we start the spin-up run using generic historic management. The emerging state space in the spin-up simulation is monitored and compared to 
the reference values, and $\mathrm{ABE}$ adapts stand management iteratively to decrease the deviation between the simulated state space and the reference conditions.

For each stand polygon an a priori stand treatment program (STP) is created based on available information on past management regimes and the current state of the system (i.e., the reference state). Such a typical STP for managed forests in Central Europe includes planting, several thinnings and a final cut (Fig. S4). For instance, the initial planting could plant trees according to the target species shares (A in Fig. S4). During the simulation the defined management steps are executed (e.g., thinnings, B, final cut C). Periodically, the state of the forest is evaluated against the available reference data. A basic evaluation compares, for instance, the growing stock and species shares emerging from the simulation with the respective reference state, and calculates a similarity score (e.g., Bray-Curtis index). When the deviation between the emerging state space from the simulations and the reference state are not satisfactorily, the STP for the next rotation can be altered. In the example in Fig. S4, the simulated share of spruce was lower than the spruce share in the reference state, indicating that spruce was likely favored by past management, either by planting spruce (C) or by favoring spruce via selective thinnings. This information is incorporated in the spin-up run, which henceforth uses a modified STP for the given stand and the next rotation (D). This process of iterative adaptation of historic management to increase the similarity between the emerging system state and the reference state is repeated several times. Whenever the simulated forest state has a higher similarity to the reference state than in previous iterations, the state of the stand is stored within a snapshot database (including all relevant information on ecosystem pools and structures), potentially overwriting previously saved states with lower similarity values. This process is executed for all stands on the landscape in parallel. The final step of the process (after, e.g., 1000 years of spin-up) is for each stand to load the saved forest state from the database (i.e., the state that had the highest similarity score relative to the reference state throughout the iterative spin-up run), 
and to create a single landscape "composite" from all of these saved stand states. This composite is subsequently used as the initial state of the landscape for scenario simulations. The spin-up procedure also creates detailed log files which can be further analyzed (e.g., regarding the deviation of the initialized landscape from the reference state). Technically, the logic of the legacy spin-up is implemented as a JavaScript library. The library is used by application specific JavaScript code (e.g., the historic management regime for the given landscape, or the calculation of similarity indices based on available data) that is provided by the user.

One big advantage of the legacy spin-up procedure is that it can accommodate varying degrees of data availability. If, for instance, only information on stand ages are available, age is the sole criterion used to determine the reference state. However, in many cases there is also information on species composition, growing stock, etc. available (as was the case in the historical data from the 1905 inventory of the landscape studied here), which can be jointly assimilated into the spin-up procedure. If density or growing stock is available in addition to age and species, for instance, the legacies of past non-stand-replacing disturbances and management operations such as thinnings can be captured more faithfully in the spin-up. However, even if no information on the reference vegetation state is available, the procedure can be used to generate a first estimate of landscape-scale vegetation structure and composition based on simulations of historic management and disturbance regimes. The legacy spin-up thus combines the advantages of a conventional spin-up (model-internal consistency of the initialized ecosystem states) with the assimilation of available data on the study system for initializing the model.

\section{Application of the legacy spin-up in the current analysis}

For the current study, our aim was to initialize the historic landscape based on stand-level forest management and planning data for 1905, extracted from historical archives. The available 
information on reference states from archival sources was species composition and age classes per stand, as well as stand-level growing stock. Consequently we defined reference states as the species-specific growing stock and age for every stand, also accounting the possibility of multiple age classes within a stand (representing multilayer and multicohort stands). We developed species and site specific a priori STPs (planting, tending, thinning and harvesting activities) based on common forest management practice in Austria during the $19^{\text {th }}$ century (Stifter 1994). Initially, the share of species in plantings was assumed equal to the reference species share for each stand. If the Bray-Curties Index, a measure for the similarity of the simulated species composition to the reference state, was above a user-defined threshold at the end of a simulation period, ABE autonomously adapted planting activities, aiming for a species composition closer to the reference state. Shade-intolerant species were planted in groups, while shade-tolerant species were planted in equal spacing in order to improve the competitiveness of shade-intolerant species, and increase the spatial realism of the emerging species distribution patterns. Tending and thinning were specified by the stand age at which these activities are conducted, the amount of timber removed in each intervention, the minimum dbh (diameter at breast height) for tree removal, and the relative share of trees to be removed per dbh class (e.g., in order to differentiate between thinnings from below and from above). The simulation period was defined by the reference stand age. A combined index including the Bray-Curtis-Similarity Index (for tree species composition) and the relative deviation from the reference growing stock level were used to determine the best approximation of the simulated vegetation to the reference state. For an initial estimate of belowground carbon pools in year 0 of the spin-up we used data of Kalkalpen National Park (KANP) as derived by Thom and others (2017) for the year 1999. Only simulated states > year 100 of legacy spin-up were considered for initialization, in order to allow belowground carbon pools to adjust to historical management. 
We started the legacy spin-up procedure from bare ground, assuming reduced nitrogen pools as described in the section "Landscape initialization and drivers" (as a result of historic management such as litter raking). We ran the legacy spin-up for 1000 years, assuming constant historic climate conditions. In total 2079 stands were simulated in the legacy spin-up, and subsequently reassembled to the landscape representing the state of forest vegetation in 1905 .

Our evaluations of the spin-up procedure indicated a good match between reference conditions determined from archival sources and simulation for tree species composition (Fig. S5) and growing stock (Fig. S6) on the landscape.

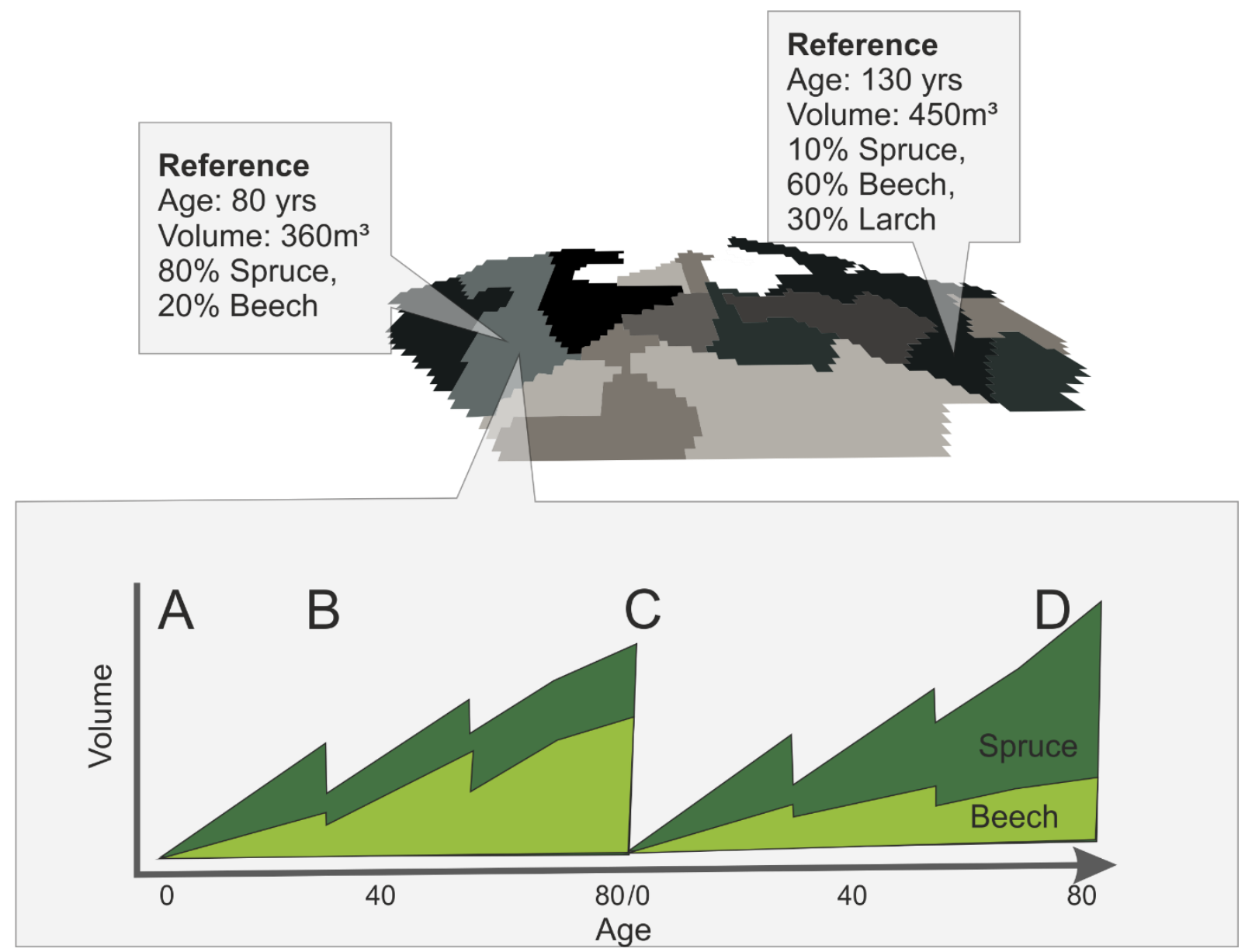


221 Fig. S4: Concept of the legacy spin-up. Upper panel: a fictitious landscape with differing

222 reference states for the spin-up. Lower panel: The development of one stand over two simulated

223 rotations over the course of the legacy spin-up. Letters A to D indicate different phases of the

224 process: A initial planting of target vegetation, B thinnings, C final cut, D modified stand

225 treatment program (STP) for the next rotation period (see text for details).

226

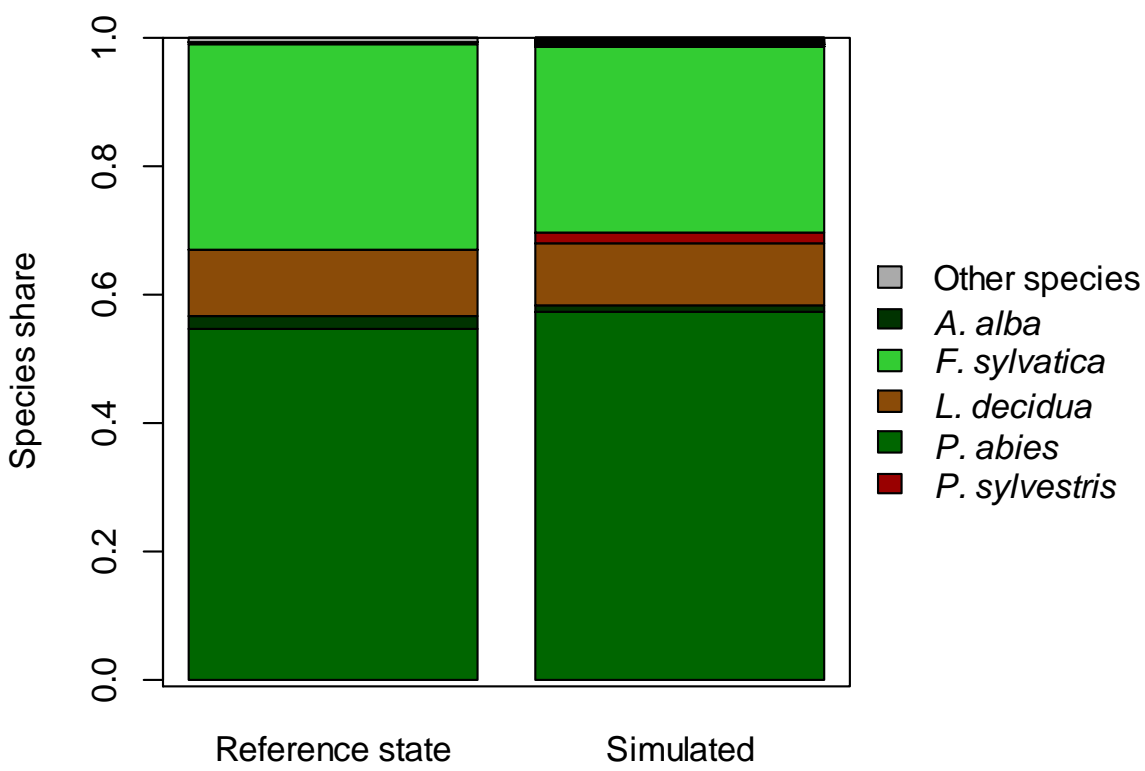

228 Fig. S5: Reference state (from archival sources) and simulated tree species composition emerging as the end point of a legacy spin-up for the year 1905. Species share refers to the relative growing stock per species $(1=100 \%)$. 


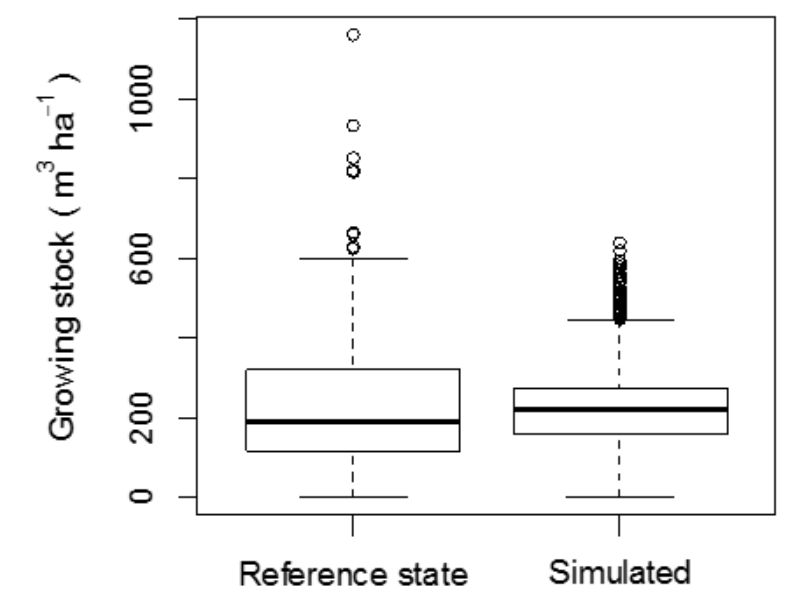

232

233 Fig. S6: Reference state (from archival sources) and simulated growing stock emerging as end 234 point of a legacy spin-up for the year 1905. Each observation refers to a stand polygon $(\mathrm{n}=$ 235 2079). Mean values: Reference state $216.9 \mathrm{~m}^{3} \mathrm{ha}^{-1}$ and simulated $207.0 \mathrm{~m}^{3} \mathrm{ha}^{-1}$. 


\section{References}

Garcia-Gonzalo, J., Peltola, H., Zubizarreta Gerendiain, A. and Kellomäki, S.: Impacts of forest landscape structure and management on timber production and carbon stocks in the boreal forest ecosystem under changing climate, For. Ecol. Manage., 241(1-3), 243-257, doi:10.1016/j.foreco.2007.01.008, 2007.

Rammer W, Seidl R. 2015. Coupling human and natural systems: Simulating adaptive management agents in dynamically changing forest landscapes. Glob Environ Chang $35: 475-85$.

Scheller, R. M., Domingo, J. B., Sturtevant, B. R., Williams, J. S., Rudy, A., Gustafson, E. J. and Mladenoff, D. J.: Design, development, and application of LANDIS-II, a spatial landscape simulation model with flexible temporal and spatial resolution, Ecol. Modell., 201(3-4), 409-419, doi:10.1016/j.ecolmodel.2006.10.009, 2007.

Schumacher, S. and Bugmann, H.: The relative importance of climatic effects, wildfires and management for future forest landscape dynamics in the Swiss Alps, Glob. Chang. Biol., 12(8), 1435-1450, doi:10.1111/j.1365-2486.2006.01188.x, 2006.

Seidl, R., Rammer, W., Scheller, R. M. and Spies, T. A.: An individual-based process model to simulate landscape-scale forest ecosystem dynamics, Ecol. Modell., 231, 87-100, doi:10.1016/j.ecolmodel.2012.02.015, 2012.

Stifter, A. 1994. Österreichs Wald - Vom Urwald zur Waldwirtschaft. Österreichischer Forstverein, Wien, Austria, pp $1-544$.

Temperli C, Zell J, Bugmann H, Elkin C. 2013. Sensitivity of ecosystem goods and services projections of a forest landscape model to initialization data. Landsc Ecol 28:1337-52. 
259 Thom D, Rammer W, Dirnböck T, Müller J, Kobler J, Katzensteiner K, Helm N, Seidl R. 2017. The impacts of climate change and disturbance on spatio-temporal trajectories of biodiversity in a temperate forest landscape. J Appl Ecol 54:28-38. 48. 
(a)

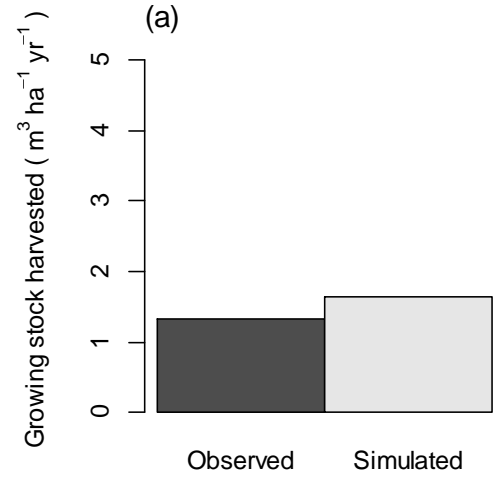

(b)

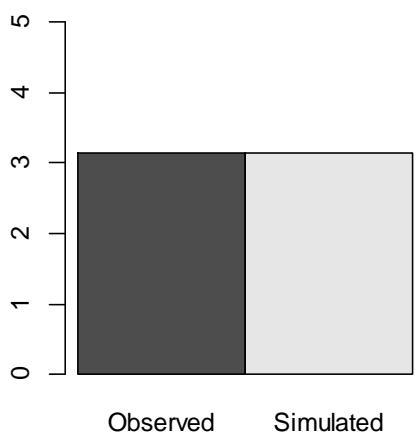

(c)

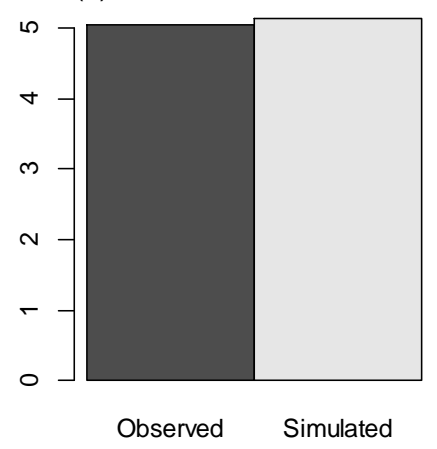

268 Fig. S7: Growing stock (timber volume over bark) harvested in the periods (a) 1924 - 1952, (b) 2691956 - 1973, and (c) 1974 - 1983, as reconstructed from archival sources (observed) and 270 simulated with iLand. Simulation data are for the baseline scenario, i.e. assuming historic 271 natural disturbance and management regimes. 


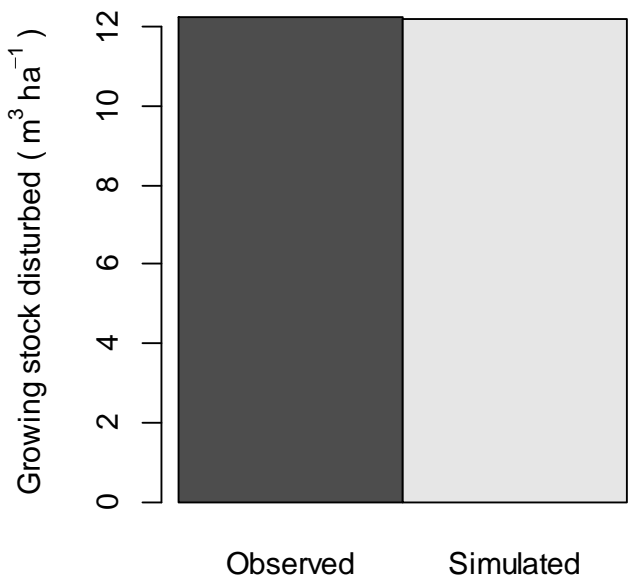

273

274 Fig. S8: Observed and simulated growing stock disturbed during the second disturbance episode 275 (2007 - 2013). Observed values were derived from disturbance inventories of Kalkalpen

276 National Park, whereas simulated values are for the baseline scenario (i.e., assuming historic 277 natural disturbances and management regimes. 


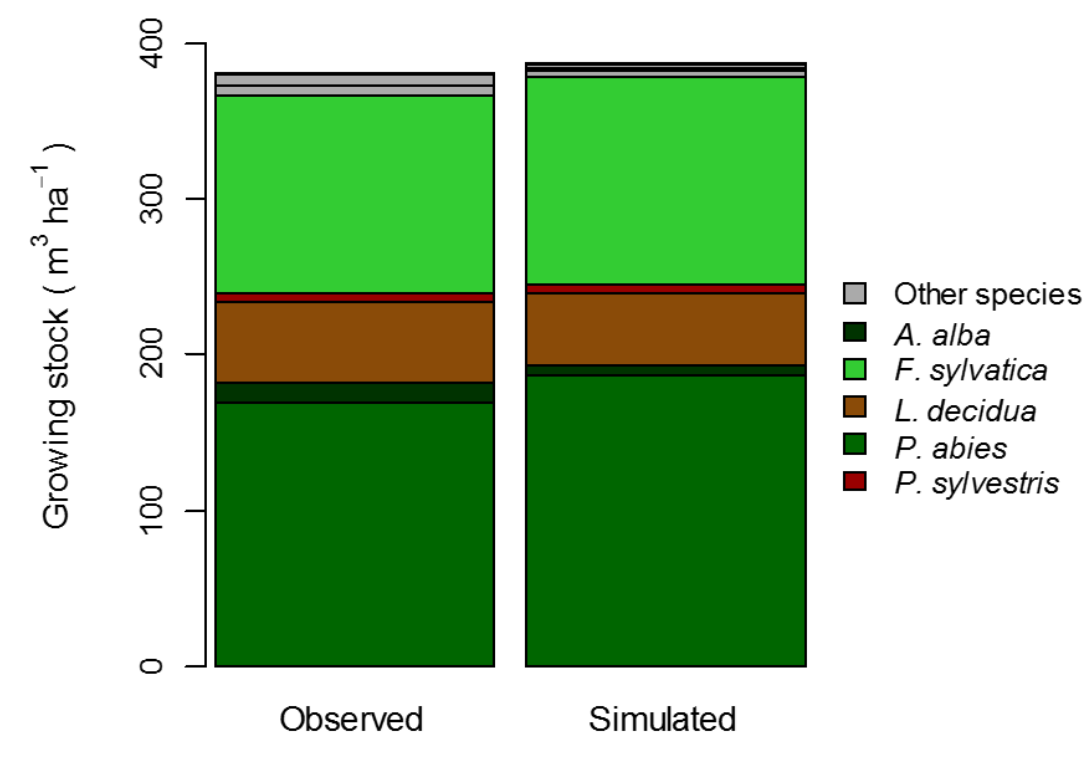

281 Fig. S9: Observed and simulated growing stock by tree species in the year 1999. Observations 282 are from forest management and planning data of the Austrian Federal Forests, whereas 283 simulated data are for the baseline scenario (i.e., assuming historic natural disturbance and management regimes). 


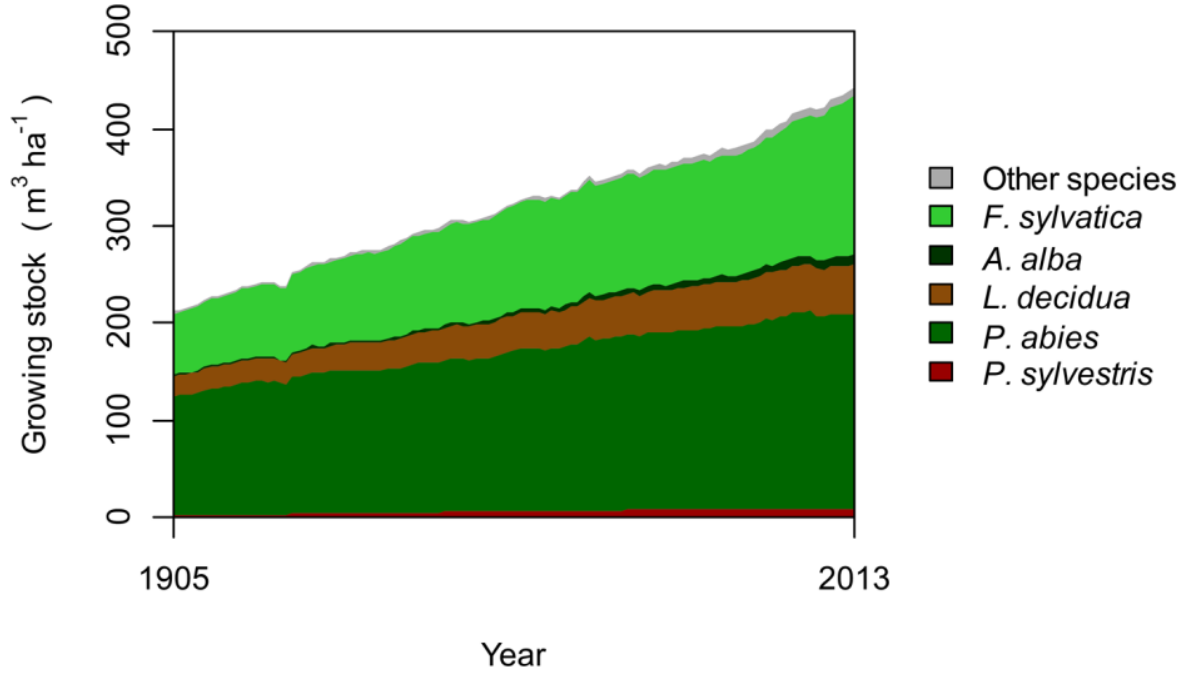

286

287 Fig. S10: Growing stock by tree species over time, reconstructed by means of simulation 288 modeling. Data are for the baseline scenario (i.e., assuming historic natural disturbance and 289 management regimes). 


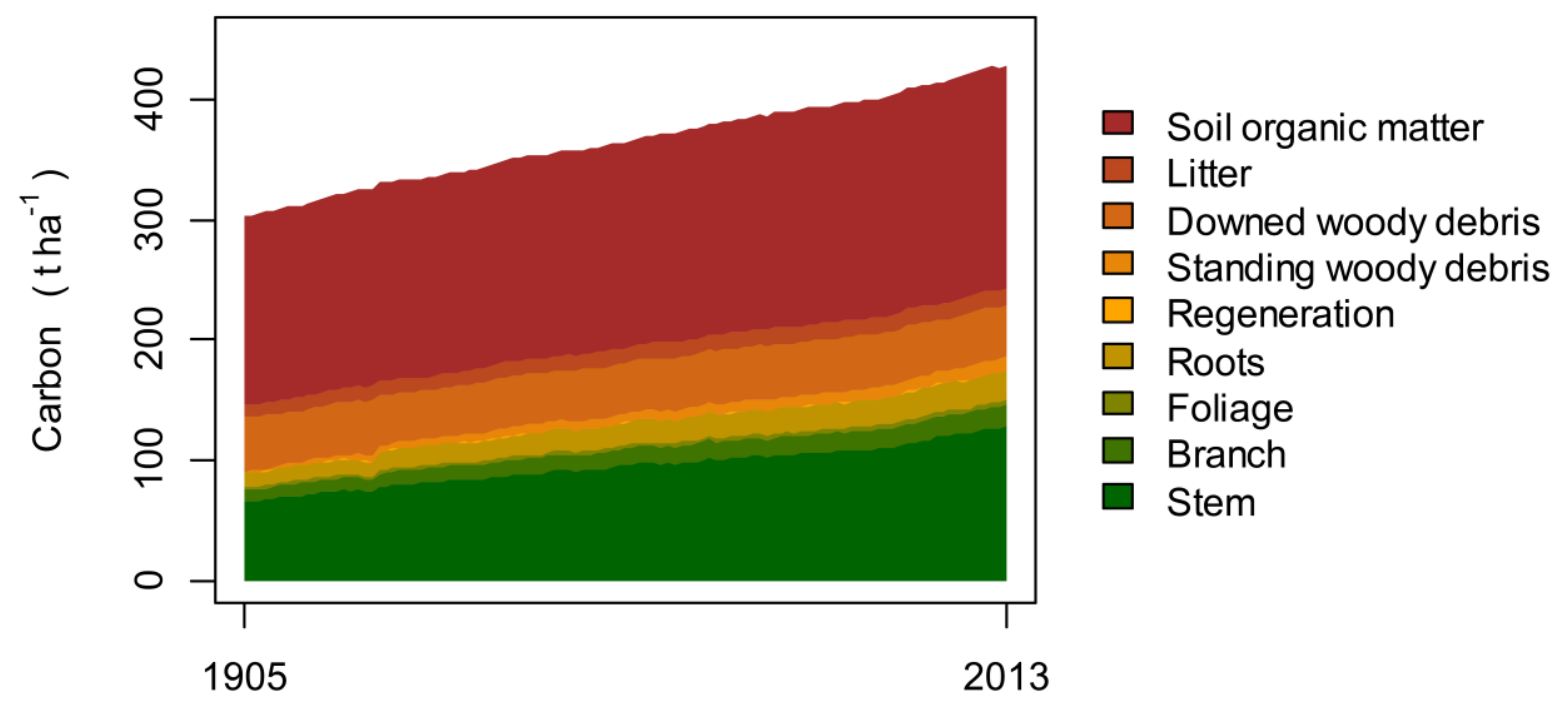

Year

292 Fig. S11: Carbon storage per compartment, reconstructed by means of simulation modeling.

293 Data are for the baseline scenario (i.e., assuming historic natural disturbance and management 294 regimes). 